\title{
How Accessible is Clean Water to the Rural Area in this Modern Era?
}

\author{
Michael Uchenna* \\ University of Nigeria, Department of Nutrition and Dietetics, Nigeria
}

*Corresponding author: Michael Uchenna, University of Nigeria, Department of Nutrition and Dietetics, Nigeria.

Received Date: March 25, 2019

Published Date: April 26, 2019

\section{Opinion}

Often times, there seems to be high rate of death toll in the rural area of which the cause is still hidden to those living in such area.

Nowadays, people suffer a slight headache and the next thing you hear is that the person is dead. This is mostly caused by intake of dirty/unclean water, but people are yet to know.

There are some identified diseases caused by unsensitized water. Such diseases include Amoebiasis, cholera, Giardia, cryptosporidiosis, etcetera. But the truth is, there are still some diseases that are yet to be known that are caused by unclean water. If this is not true, the symptoms and medications of the aforementioned diseases has been in one way or another related to those living in such an area yet, they still die of water borne disease contamination irrespective of their age or gender.

There is a question that linger in my mind

Why are People Still Dying of Water Borne Diseases in this Era?

In the world of today, people still die of water borne disease due to either 'ignorance ' or lack of finance. let us not forget that our target is at those living in the rural areas. A situation where one is been told look, you are suffering from this particular disease and it was caused by the type of water you drink and the question you hear from the person in response is, have you ever seen anyone who has died of water borne disease before? or you had that someone died because of water. is water not meant for drinking? you will be discouraged to enlighten the person on how to cure such disease. Secondly, when one knows the cause of the disease and what can cure the disease but due to lack of finance, such a person could not access the hospital, the only option left for the disease is to kill such a person. The governance in most countries more especially in West African countries is too poor that those elected politic with people's lives as provision of basic ammunition are considered a later obligation. According to World Health Organization, 3.4 million people die of water borne disease in the whole world of which over 3.2 million are from the West African countries. some people travel a very long distance just to fetch drinking water which are not treated before intake. if these people can be provided with water, half treated, the figure will drastically reduce by at least $75 \%$.

\section{Conflict of Interest}

No Conflict of Interest.

\section{Aknowledgement}

None. 